\title{
STRUCTURES AND MATERIALS TECHNOLOGIES FOR EXTREME ENVIRONMENTS APPLIED TO REUSABLE LAUNCH VEHICLES
}

\author{
Stephen J. Scotti*, Christopher $\mathrm{Clay}^{+}$, Marc Rezin ${ }^{\ddagger}$
}

\begin{abstract}
$\underline{\text { Abstract }}$
This paper provides an overview of the evolution of structures and materials technology approaches to survive the challenging extreme environments encountered by earth-to-orbit space transportation systems, with emphasis on more recent developments in the USA. The evolution of technology requirements and experience in the various approaches to meeting these requirements has significantly influenced the technology approaches. While previous goals were primarily performance driven, more recently dramatic improvements in costs/operations and in safety have been paramount goals. Technologies that focus on the cost/operations and safety goals in the area of hot structures and thermal protection systems for reusable launch vehicles are presented. Assessments of the potential ability of the various technologies to satisfy the technology requirements, and their current technology readiness status are also presented
\end{abstract}

\section{Introduction}

Though the Space Shuttle has been an operational reusable space transportation system for over 20 years, only incremental improvements in the structure and thermal protection systems (TPS) have been incorporated. The excellent performance of the structure and thermal protection system for nominal missions, the expense of flight qualifying major modifications to the system, as well as the reluctance to make modifications to an operational system have all contributed to the slow deployment of new thermalstructural technologies on the Shuttle. With rising interest in new vehicles such as the Orbital Space Plane (OSP), the Space Operations Vehicle (SOV), and a Next Generation Launch Vehicle (NGLT) comes an opportunity to deploy technology improvements that have been slowly developing since the 1970's. There are two motivations for incorporating new technologies in a new launch system: the high maintenance overhead

\footnotetext{
* Head, Metals and Thermal Structures Branch, NASA Langley Research Center, MS 396, Hampton, Virginia, + Deputy Chief, Aeronautical Systems Sector, Air Force Research Labs, WPAFB, Ohio, USA \$ TPS Lead, NGLT \& OSP Programs, NASA Ames Research Center, Moffett Field, California, USA This material is declared a work of the U.S. Government and is not subject to copyright protection in the United States.
}

and long refurbishment times required for the present Shuttle thermal-structural system, and the desire for large improvement in safety over the present system. Some background information may be helpful in understanding these two points.

The Space Shuttle airframe in most respects utilizes conventional aluminum alloys using commercial aircraft design practices. This approach led to very low risk for developing the airframe structure. However, the severe aerothermal environment during reentry subject to a number of design and operational constraints (e.g., smoothness to avoid thermal load amplification, low weight, low acquisition and operational costs, mechanical and thermal compatibility with the primary structure) required development of a high-performance thermal protection system (TPS) to protect the low-temperature primary structure. The present silica tile and blanket thermal protection system, applied to the majority of the Shuttle surface area, was selected as the best compromise of the many proposed approaches to meet these constraints and it also allowed a decoupling of the structural design from the thermal protection system design to a large degree. However, service experience with the Shuttle TPS has revealed long refurbishment timelines and high operational costs that were not anticipated during the design phase. In one study ${ }^{1}$, the maintenance burden for the thermal protection system was estimated at nearly 32,000 hours per mission. Clearly, neither a commercial nor a military operational vehicle would be viable with this level of required maintenance. In addition, probabilistic risk analyses performed for the Shuttle Reaction Cured Glass (RCG) coated tile system² 
estimated the probability of loss of vehicle was approximately 1 in 1000 due to this system alone. Sensitivity to discrete events such as occurred during the Columbia STS-107 mission also demonstrates the need to improve the safety of space transportation systems.

The present paper provides an overview of technology advances in two areas that togetther may yield major improvements to the operational efficiency and safety of new reusable space transportation systems.

Advances in reusable thermal protection systems with greatly improved operational and safety features for the majority of the vehicle outer mold line - the acreage TPS - are described first. Subsequently, technology advances that allow the replacing of integrated lowtemperature primary structure/thermal protection system assemblies with simpler systems utilizing hot structure components are summarized.

\section{Acreage Thermal Protection Systems}

The state-of-the-art for operational acreage TPS is the Space Shuttle (Figure 1). The Shuttle acreage thermal protection system consists of insulations that are processed to also serve as the vehicle outer mold line. The windward side of the vehicle is required to maintain critical geometric constraints on the vehicle contours while having enough structural integrity to transmit the local airloads to the primary structure. The Shuttle silica-based tile system is still one of the most thermally efficient approaches to meet these design requirements. However, the damage tolerance of this system is relatively low, and as described previously, significant improvements to reduce refurbishment time are desired. A large part of the current investment is focused on ceramic tile, blanket and metallic thermal protection system improvements. Tiles and blankets are being developed to be more damage resistant and to be applicable to the more demanding thermal regions of the vehicle, such as tiles for leading edges and blankets for windward surfaces. Both ceramic tiles and blankets, however, still require waterproofing between flights, although development of non-toxic, spray-on materials may lessen the maintenance burden associated with this task. Metallic TPS with encapsulated insulation can avoid the need to be re-waterproofed, and thus may offer a benefit in operability.

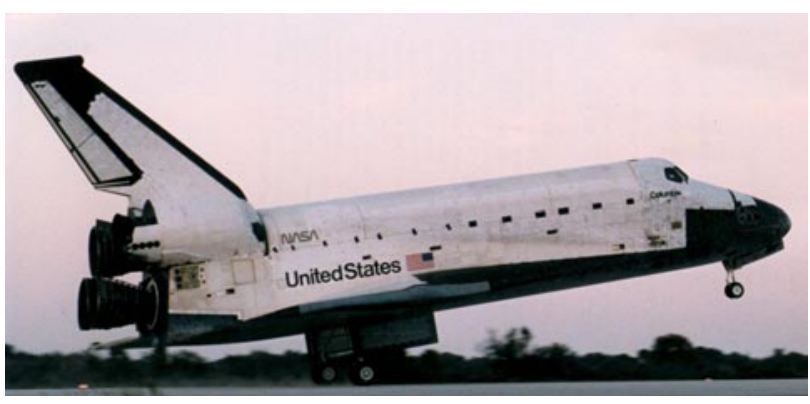

Figure 1. NASA Space Shuttle

The salient features and a summary of the progress achieved with Durable Acreage Ceramic TPS, Metallic Thermal Protection Systems, and Integrated TPS using Ceramic Matrix Composites and Mechanically Attached Blankets are summarized in the subsequent subsections. In addition, philosophies for Rapid Turnaround Operations for TPS are discussed.

\section{Durable Acreage Ceramic TPS}

The silica blanket-type TPS used on a substantial portion of the Shuttle leeward surfaces is known as Advanced Flexible Reusable Surface Insulation (AFRSI). This system has performed admirably, but it is subject to surface erosion and impact damage, potentially requiring rather labor-intensive repair. AFRSI is also limited to $1200^{\circ} \mathrm{F}$ surface temperatures and its outer surface is too rough for use in aerothermal environments where the boundary layer is relatively thin, such as the windward side of a re-entry vehicle. Boeing Huntington Beach has recently developed an advanced quilted blanket TPS called Conformal Reusable Insulation (CRI) to expand these performance boundaries.

In order to improve the durability of these blanket TPS, the outer surface fabric layer and coating have been modified, producing a ceramic matrix composite (CMC). Several different fiber types, fabric weaves, and matrix compositions were evaluated, resulting in a range of performance characteristics that can be tailored to suit the demands of the particular use environment. Initial assessments of the durability of this advanced blanket surface have produced very encouraging results relative to the Shuttle-era TPS.

In addition to improving the durability of blanket TPS, CRI extends the operational surface temperature limit to the $1800^{\circ} \mathrm{F}-2000^{\circ} \mathrm{F}$ range, depending on the particular matrix composition selected. The ceramic batting material, which is sandwiched between the fabric facesheets, is made from ceramic fiber that is processed using a novel method developed specifically for the CRI effort. This rigidization method greatly aids the fabrication of CRI, dramatically improving the 
flatness of the resulting blanket as well the dimensional accuracy of the finished parts.

Lastly, the CMC outer layer is cured in a manner that produces a surface that is compatible with much thinner boundary layers than the AFRSI material. The greatest degree of surface smoothness is present on a type of CRI that incorporates a second fabric layer into the $\mathrm{CMC}$ after the blankets are installed on the vehicle; this second layer covers both the quilting stitches and the gaps between CRI panels. This degree of smoothness is expected to permit use of CRI blankets on the windward surfaces of future vehicles, greatly reducing the part count for the windward TPS; CRI panels can be as large as several feet square. CRI is currently baselined in a windward location on the X-37 vehicle. Various types of CRI which have been developed are illustrated in figure 2 along with a Shuttle LI-900 tile for comparison.

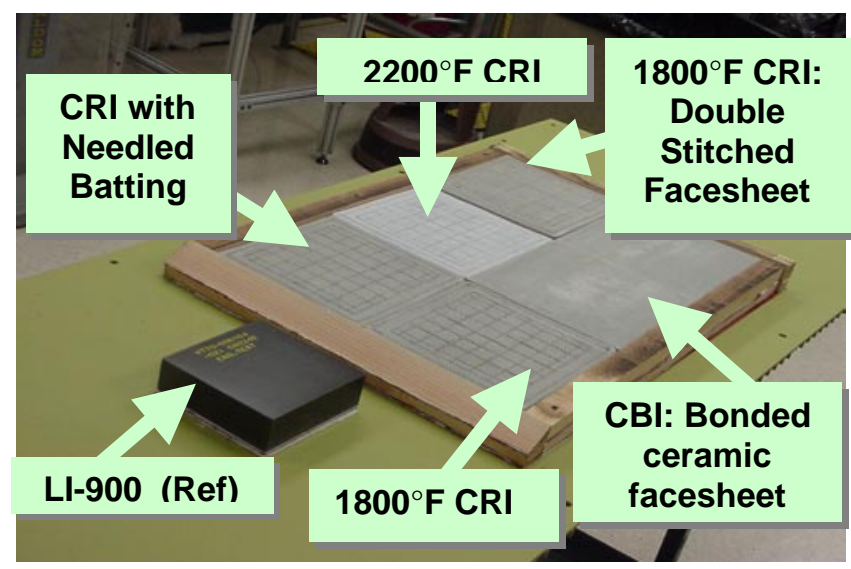

Figure 2. Various Types of CRI

\section{Metallic Thermal Protection Systems}

The damage tolerance of a ductile metal skin is one of the major advantages of a metallic thermal protection system. An excellent summary of the history of metallic thermal protection systems can be found in reference 3. Briefly, metal heat shields were used on the leeward faces of the Mercury and Gemini capsules and were one of the systems considered for the Space Shuttle in the 1970's. After the selection of a ceramic thermal protection system for the Shuttle, NASA Langley continued the development of metallic systems. There were several variations of note: radiative heatshields ${ }^{4}$, and multiwall tiles ${ }^{5}$ which led to the Metallic TPS developed by Goodrich

Aerostructures (formerly Rohr) for the X-33 program ${ }^{6}$. Following these developments further improvements were made resulting in the ARMOR TPS ${ }^{7}$ and the Oceaneering Metallic TPS developed for Next
Generation Launch Vehicle. These latter three systems are described subsequently.

\section{The X-33 Metallic TPS}

One of these key technologies to be demonstrated in the X-33 program was the metallic Thermal Protection System. The X-33 TPS $^{6}$ was intended to yield "an order-of-magnitude reduction in maintenance and inspection requirements as compared to existing Shuttle TPS", and was the largest developmental effort of reusable thermal protection systems since the Space Shuttle Program. The basic TPS panel design is shown in figure 3, and consisted of an Inconel honeycomb sandwich structure, inserts, edge closures, doubles primary and secondary seals, and encapsulated fibrous insulation. The basic standoff bracket consisted of a 4legged rosette. The majority of the flight TPS hardware was designed, analyzed and approved for manufacture and flight. A significant level of preflight testing and substantiation analysis had been conducted to validate the design before the program was cancelled.

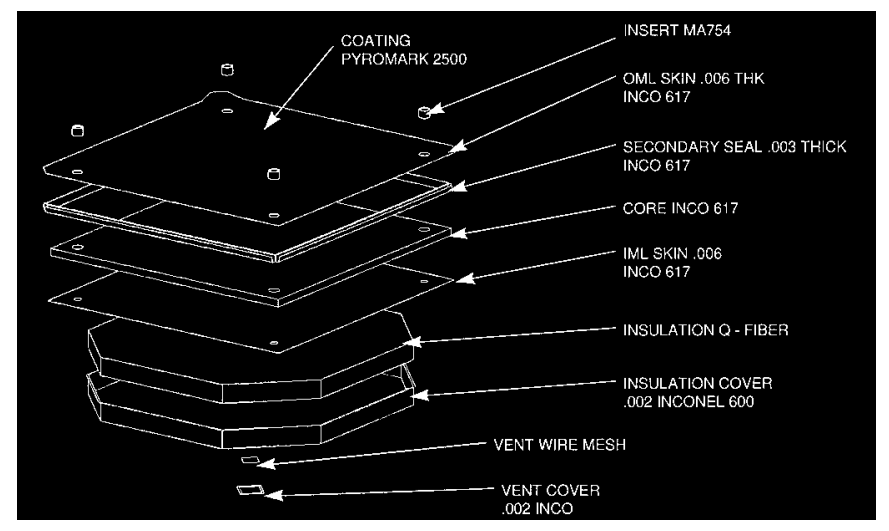

Figure 3. X-33 Metallic TPS (From Goodrich Aerostructures)

\section{The ARMOR TPS}

The ARMOR TPS ${ }^{7}$ was developed to incorporate "lessons learned" from prior metallic TPS concepts (e.g., Multiwall, X-33). Specifically, it was designed to eliminate thermal radiation in the gaps between panels, to provide attachment and edge sealing on the cool interior side of the panels, and to better decouple the thermal expansion of the outer and inner surface of the TPS panels. Hypervelocity impact resistance and panel flutter effects were also studied in depth (references 8 and 9). The salient design features are shown in figure 4. In addition, a very lightweight standoff system was developed for connecting the TPS panels to stiffened structures, which provided thermal accommodation with the primary structure - either dry structure or a 
cryogenic tank - as well as the interface for the panel edge seal. This approach is shown in figure 5. The ARMOR TPS and TPS integration structure have been matured to the point that full-scale panels have been manufactured to NASA's design by Goodrich Aerostructures, and validations tests have been performed. These validation tests have included twopanel array thermal vacuum chamber tests, and a series of tests where a four-panel ARMOR TPS array, the standoff system, and a full-scale composite cryotank subcomponent underwent cryogenic, elevated temperature, and tank pressurization simulations as an integrated system (yet to be published).

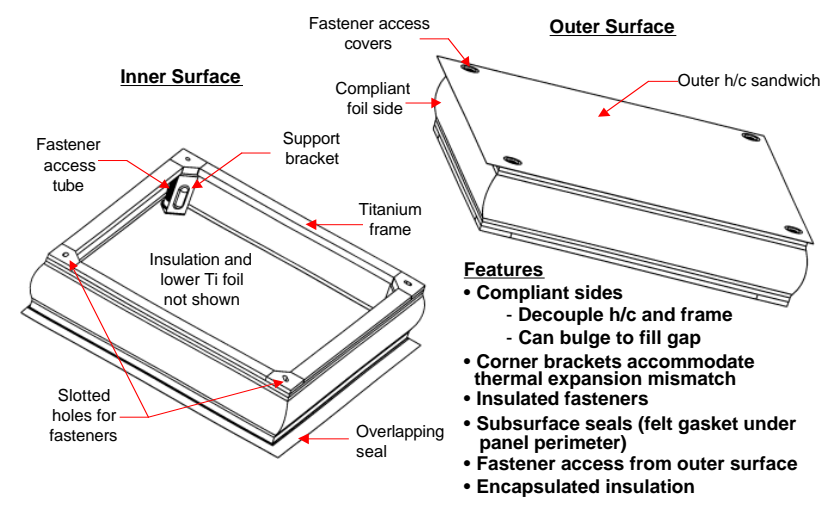

Figure 4. Salient features of ARMOR TPS (From Reference 7)

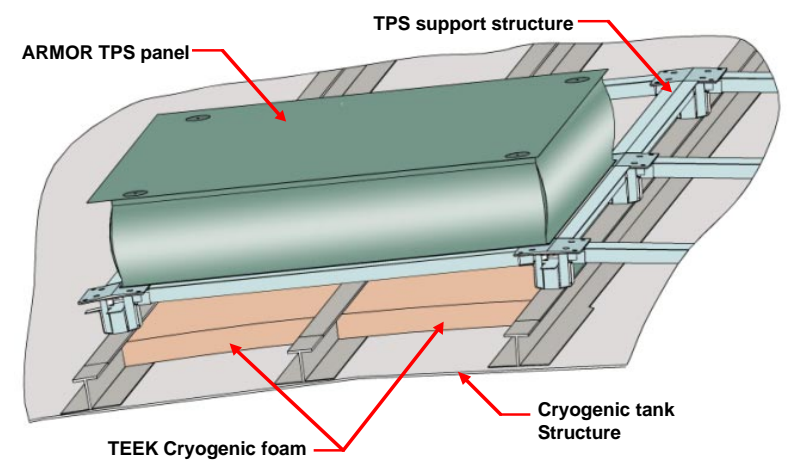

Figure 5. ARMOR TPS with Standoff Support Structure (From Reference 7)

\section{The Oceaneering Metallic TPS}

The Oceaneering Metallic TPS is being developed under the NASA Next Generation Launch Technology Program. This approach differs from prior approaches in that it utilized additional outer mold line seals that form a grid to frame the individual TPS panels as shown in figure 6 . This frame is specifically intended to provide an improved rain and pressure seal on the outer face of the TPS. Significant work to validate the seal has been performed. A MIL- STD- 810m506.4 Wind Driven Rain Test was completed which resulted in a water weight gain significantly below the 5\% TPS mass increase criteria used by Shuttle, and static leakage performance of the full panel sealing system was successfully completed. Planned tests to complete development of the Oceaneering Metallic TPS are arc jet testing, cryotank-TPS integration tests, low velocity impact testing, thermo-acoustic testing, radiant pressure testing, high temperature wind tunnel (Mach 7) testing, and F- 15B flight through rain durability tests.

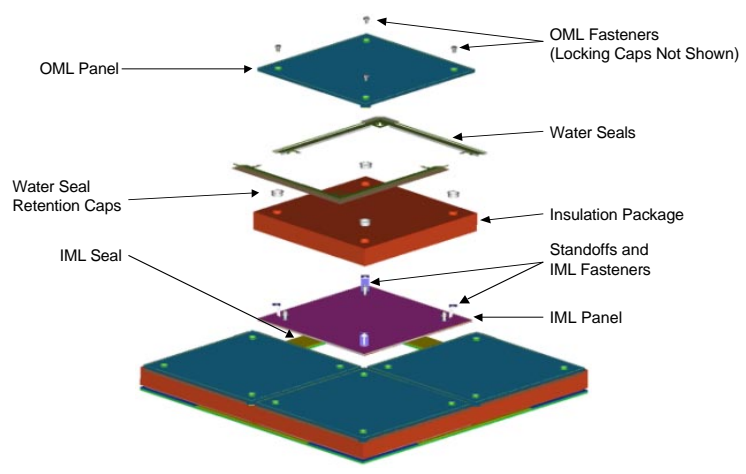

Figure 6. Oceaneering TPS

Integrated TPS using Ceramic Matrix Composites Integrated thermal protection systems for airframe applications are being developed to improve the robustness of early generations of parasitic TPS. These more robust concepts typically use a ceramic matrix composite (CMC) as the outer mold line material, either as a stiffened laminate or as the outer skin of a sandwich construction, to provide a more robust interface to man-made and natural environments. Such concepts still require interior or backside insulation to limit heat transfer, as well as a means of attachment, typically bonding or mechanical attachment.

One approach under investigation is to apply oxideoxide CMCs to Alumina Enhanced Thermal Barrier (AETB) insulating tiles. Figure 7 shows a picture of this concept, developed by Boeing under Air Force funding, undergoing impact testing. Figure 8 is a comparison of the impact energies needed by various $\mathrm{CMC} /$ tile concepts investigated in this program to induce visible damage. As shown, the best $\mathrm{CMC} / \mathrm{tile}$ concept resulted in approximately an order of 
magnitude improvement in threshold impact damage energy over Reaction Cured Glass/Toughened UniPiece Fibrous Insulation (RCG/TUFI) coated tile.

Through-thickness reinforcement can be added as a method for strengthening the attachment of the CMC facesheets to the AETB ceramic insulation. In this approach, oxide $\mathrm{CMC}$ rods are used to penetrate the insulation and the facesheets on either side. A crosssectional view of this concept, developed by Aztex under Air Force funding, is shown in figure 9, which depicts a specimen undergoing a 3-point bend test. Results have been promising, but this concept is still in the early stages of development and requires considerably more development and testing to assess its full potential.

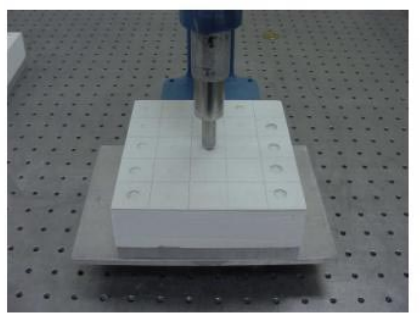

$>90^{\circ}$ Impact test (Gardner Impact Tester) $6^{\prime \prime} \times 6^{\prime \prime} \times 1.5^{\prime \prime}$ specimen

$>$ Test was performed on initial Co-Cured CMC/Tile concept

$>$ Evaluated relative impact resistance and determined effects of fabric conditioning and CMC facesheet thickness

\begin{tabular}{|c|c|c|c|c|}
\hline $\begin{array}{c}\text { Specimen } \\
\#\end{array}$ & Substrate & Fabric & Treatment & $\begin{array}{c}\text { \# of Fabric } \\
\text { Plies }\end{array}$ \\
\hline 1 & $18 \mathrm{pcf}$ & $\begin{array}{c}\text { Nextel } \\
720\end{array}$ & None & 2 \\
\hline 2 & $18 \mathrm{pcf}$ & $\mathrm{N} 720$ & None & 4 \\
\hline 3 & $18 \mathrm{pcf}$ & $\mathrm{N} 720$ & Aged $2400^{\circ} \mathrm{F} 2 \mathrm{hrs}$ & 2 \\
\hline 4 & $18 \mathrm{pcf}$ & $\mathrm{N} 720$ & Aged $2400^{\circ} \mathrm{F} 2 \mathrm{hrs}$ & 4 \\
\hline 5 & $16 \mathrm{pcf}$ & $\mathrm{N} 312$ & Aged $1800^{\circ} \mathrm{F} 100 \mathrm{hrs}$ & 2 \\
\hline 6 & $16 \mathrm{pcf}$ & $\mathrm{N} 312$ & Aged $1800^{\circ} \mathrm{F} 100 \mathrm{hrs}$ & 4 \\
\hline
\end{tabular}

Figure 7. Impact Test Performed on Co-Cured CMC/ Tile Concept

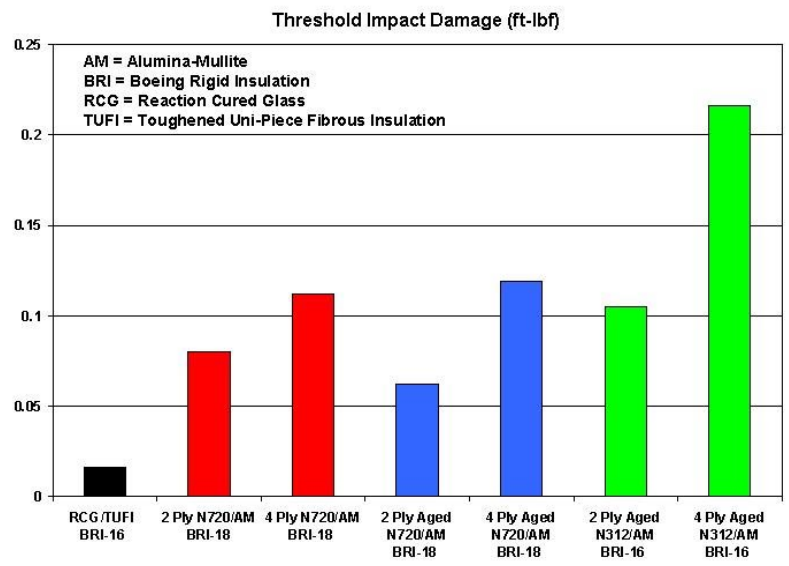

Figure 8. Impact Test Showed Significantly Higher Energy Needed to Damage a Hybrid CMC/Tile Surface
Another approach to integrated TPS with ceramics abandons the use of rigid ceramic insulation and incorporates a three-dimensional CMC thermal protection structure in a manner similar to metallic TPS. This approach uses a structural CMC framework that provides full enclosure for lightweight insulation and is either mechanically attached or bonded to the primary structure. The CMC outer facesheets can be sized to provide the desired amount of damage resistance. To date, both oxide and non-oxide CMC designs have been fabricated and tested under thermal and acoustic loading using this design approach. Figure 10 is a picture of a bonded oxide CMC concept, developed by COI Ceramics under Air Force contract, after fabrication and prior to testing. These concepts are also still in early development and require additional design, analysis and testing to fully develop their capability.

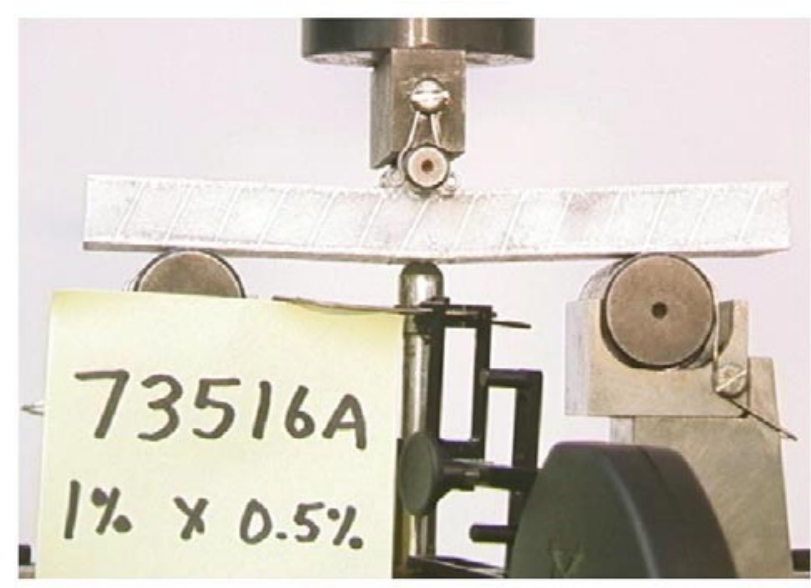

Figure 9. Aztex Z-Direction Reinforced Specimen After 3-Pt Bend Test

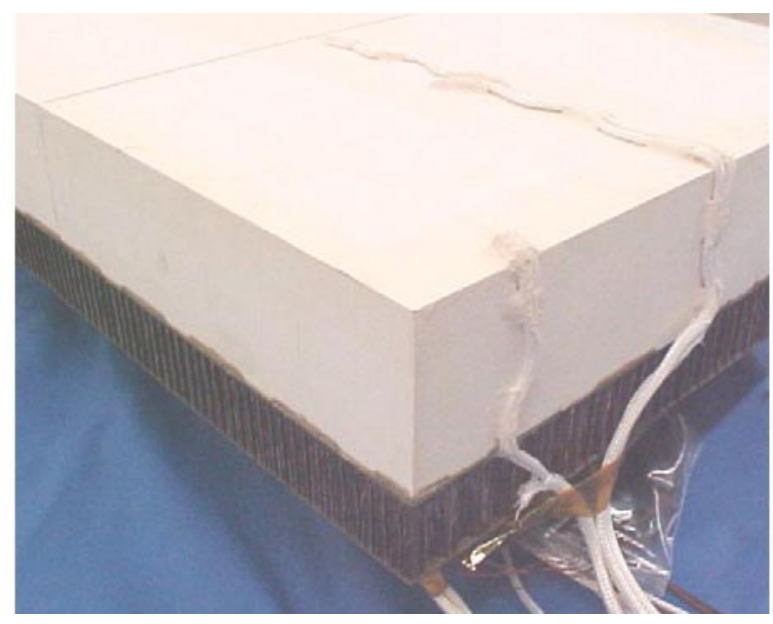

Figure 10. COI Ceramics Oxide-Oxide CMC TPS Concept 


\section{Mechanically Attached Blanket TPS}

Another effort seeks to mechanically attach flexible ceramic blanket TPS. While such TPS requires rewaterproofing and currently does not provide as much damage resistance as CMC faced TPS, it nonetheless offers an approach for easy removal of this relatively inexpensive TPS to facilitate vehicle turnaround. This concept also can allow a higher TPS-structure interfacial temperature than bonded blanket TPS that can reduce the overall TPS thickness required, and hence weight. The mechanically attached flexible ceramic blanket concept is shown in figure 11. In figure 12, one blanket is removed, revealing the blanket-to-blanket seal and multi-layer blanket stack that is possible with mechanical attachment.
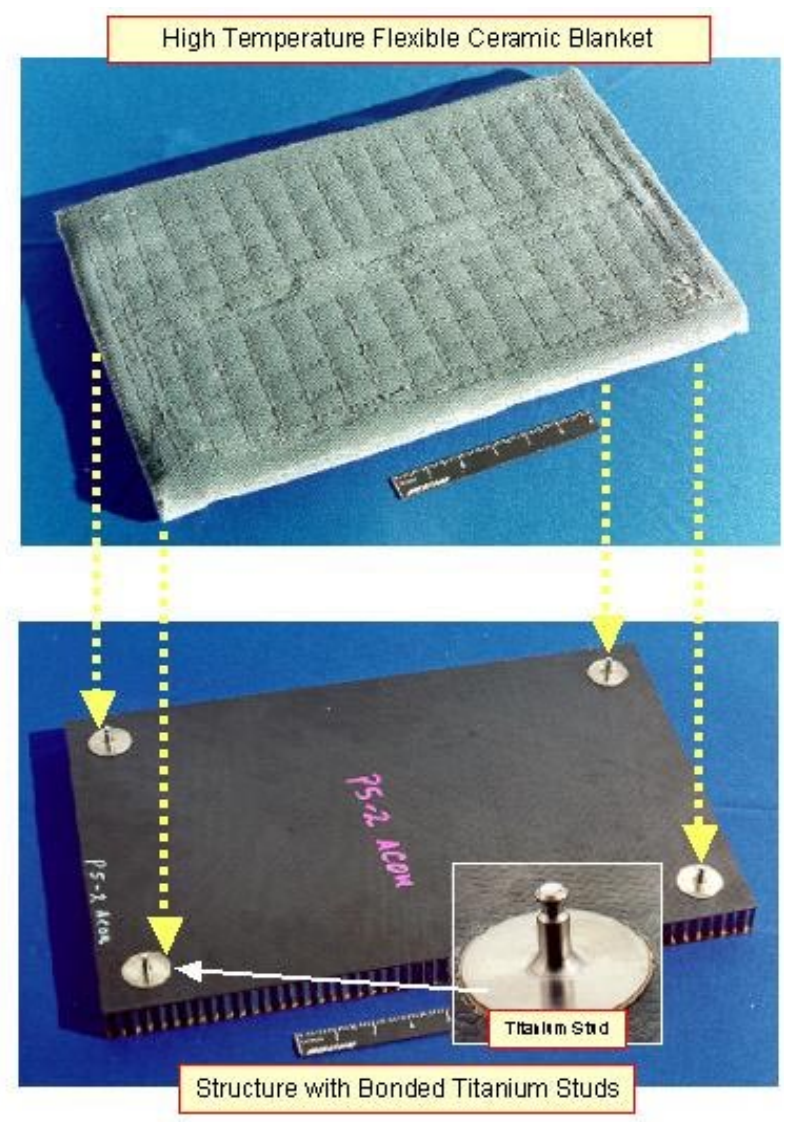

Figure 11. Mechanically Attached Nextel 440 Flexible Ceramic Blanket TPS

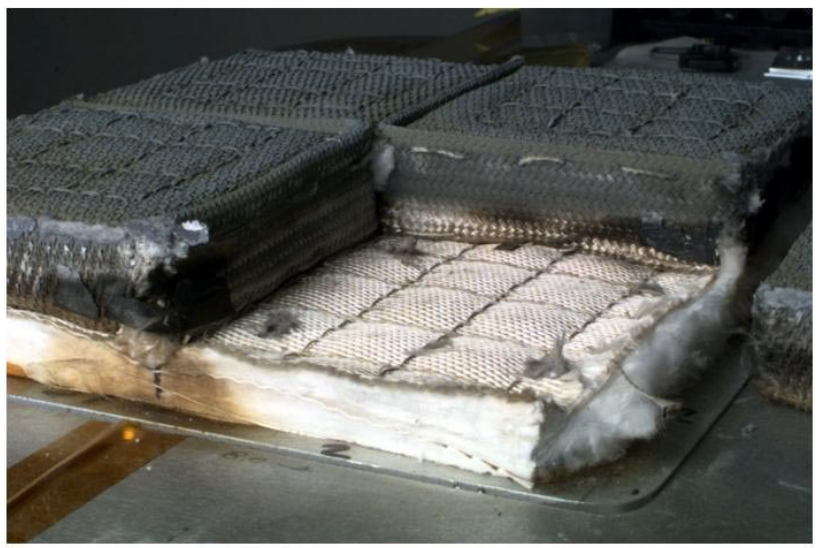

Figure 12. Mechanically Attached Blanket TPS Seal Test Article

\section{Rapid Turnaround Operations for TPS}

The servicing of the Shuttle TPS between flights is a significant contributor to the overall turnaround time allocation for the overall vehicle. As such, any decrease in the time required for the inspection, repair, and re-waterproofing of TPS can have a substantial impact on the operational availability for any reusable launch vehicle. To this end, Boeing Huntington Beach has investigated several approaches for reducing the time and effort required to perform each of these functions.

Of course, the best way to reduce the need for inspection and repair is to use a TPS that is very tolerant of the environment in which it is being operated. Several such advanced systems have been described earlier in this text. However, any TPS will at some point incur a certain degree of damage. The critical question whether this damage is of an extent or type that requires attention before the vehicle can fly again. Boeing and NASA have collaborated to develop a multi-axis optical inspection system that has the potential for scanning the surface of a vehicle's TPS and determine whether any given damage is beyond the repair threshold for the material in that particular area of the vehicle. This system also incorporates a "paperless" dispositioning feature that greatly reduces the amount of time spent filling out and tracking of the necessary documentation for each part and process related to any space vehicle.

If damage that requires repair is detected, an efficient, highly reliable repair method is needed. As part of the Boeing Rapid Turnaround Operations effort, rapid plug and patch repair methods were developed for ceramic tile and CRI TPS, respectively. Preliminary assessments have shown these repairs to have nominal 
environment durability approaching that of the undamaged TPS. Further characterization is required to determine their ultimate reliability, but these repair methods are expected to exhibit "graceful deterioration"; if they become compromised, the changes will be initially benign but detectable and occur over several flights.

Re-waterproofing is currently a very time consuming process for the Shuttle, utilizing toxic chemicals that present a hazardous worker environment. Though it's not needed between each and every flight, the process is extremely labor intensive; each ceramic tile and blanket must be injected with re-waterproofing compounds using an array of syringes. Boeing has been able to modify the composition of the re-waterproofing solution so that it can be applied using a very rapid spraying technique, as shown in figure 13, and is no longer hazardous for the workers to apply.

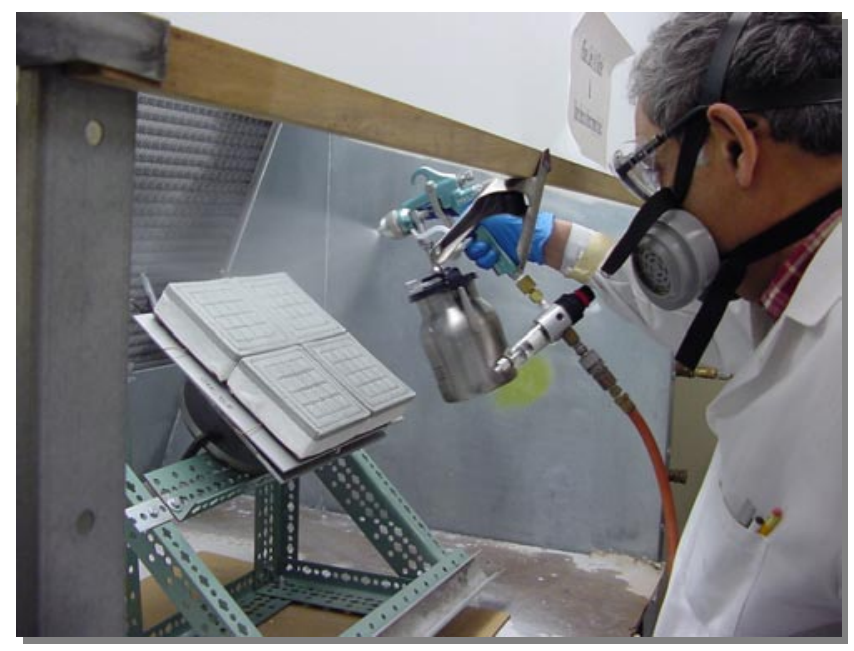

Figure 13. Spraygun application of Rapid ReWaterproofing on a small array of CRI blankets

\section{Hot Structures Technology}

Hot structures for hypersonic vehicles debuted with the $\mathrm{X}-15$ hypersonic research vehicle. Because of the short flight duration, the Inconel- $X$ and titanium alloy metallic primary structure was a heat-sink design. After this program, the immaturity of design and materials technologies prompted a long hiatus in hot structures development until a significant focused effort during the ambitious National AeroSpace Plane (NASP) program (see Reference 10). Hot structures can be readily inspected, and it is anticipated that they can be designed to be damage tolerant using standard aircraft design practices, so they offer good potential for achieving "airline-like" operations. In addition, the ability to operate a structure without a TPS allows for efficient aerodynamic characteristics that are desirable for hypersonic aircraft (e.g. thin wings). However, the complexity of the structural design problem is compounded with the addition of thermal loads from the severe aerothermal environment. Progress in hot structures is very dependent on progress in materials and fabrication processes as well as development of thermal-structural designs that allow for efficient mechanical load transfer while accommodating thermal loads at low stress levels. Lightly loaded secondary structures such as control surfaces and aerodynamic fairings can most readily be designed as hot structures, while highly loaded structures such as wings, fuselage, and propellant tanks become progressively more challenging. In the following sections, processing for metallic materials and composites, and mechanical joint design methodology for ceramic matrix composites are summarized. Advances for one specific concepts, a hot aeroshell fuselage fairing, is also described.

\section{Processing for Metallic Materials and Composites}

Metallic materials are of interest for hot structures because of the large experience base in designing metallic structures for aircraft applications. However, the unique materials issues to be address for metallic hot structures are the high temperature material systems themselves, the processing of these systems into useful product forms, and the fabrication of these product forms into practical structures. A material system that has shown significant promise for high temperature use is TiAl, also known as gamma titanium aluminide. This material has undergone significant improvements over the last 10 years and is now being produced in ingot form with room temperature elongation properties that are approaching values needed for practical structures $(\sim 1.5 \%)$. The properties of monolithic TiAl of interest at high temperature are strength and creep resistance. Developments in Titanium and TiAl materials summarizing processing improvements of thin gauge monolithic sheet and of metal matrix composites follow.

\section{Thin Gauge TiAl}

Because of the low room temperature ductility of TiAl, the commonly used ingot metallurgy processes become difficult and require numerous processing steps. The thin gauges extensively used in aircraft skins can be formed with these ingot metallurgy processes, however exploration of alternate approaches having fewer processing steps and potentially better properties are being actively explored. A new approach for the efficient manufacture of TiAl foil with improved ductility is described in reference 11. Such foil can be used in the manufacture of metallic TPS (described previously) or in the manufacture of metal matrix composites (described subsequently). The process 
utilizes the plasma spray deposition of pre-alloyed powders, followed by consolidation via vacuum hot pressing and heat treatment to produce $\mathrm{TiAl}$ foil in relatively few processing steps. It also eliminates the "canning" requirements of ingot rolling processes. The objective was to produce a very clean material (low interstitial content) with a highly refined, homogeneous microstructure placed in a fully lamellar condition. Table 1 shows the results of the tensile tests for specimens prepared using this process compared with typical tensile properties of TiAl sheet processed by more conventional means ${ }^{12}$. Although the new processing route had not been optimized, the yield strength was higher than the conventionally processed material, but the RT ductility was lower, presumably due to surface roughness and residual macro- and micro-porosity.

Table 1. TiAl room temperature tensile data.

\begin{tabular}{|c|c|c|c|c|c|}
\hline & $\begin{array}{c}\mathbf{E} \\
\mathbf{G P a}\end{array}$ & $\begin{array}{c}\text { UTS } \\
\mathbf{M P a}\end{array}$ & $\begin{array}{c}\text { YS } \\
\mathbf{M P a}\end{array}$ & $\begin{array}{c}\mathbf{e}_{\mathbf{p}} \\
\mathbf{\%}\end{array}$ & $\begin{array}{c}\mathbf{e}_{\text {tot }} \\
\mathbf{\%}\end{array}$ \\
\hline Ref. 11 & 162 & 505 & 496 & 0.24 & 0.55 \\
\hline Ref. 12 & 169 & 484 & 397 & --- & 1.40 \\
\hline
\end{tabular}

Metal Matrix Composites of Ti and TiAl High temperature metal matrix composites (MMC) were extensively investigated during the NASP program. These tasks and subsequent investigation of these material systems focused on advanced $\mathrm{Ti}$ and intermetallic $\mathrm{MMC}$ 's for $1200^{\circ} \mathrm{F}-1500^{\circ} \mathrm{F}$ applications. The goal then and now is to develop lightweight hightemperature MMC's for robust low-cost metallic hot airframe structure, as illustrated in figure 14 .

Efficient joining and attachment processes for MMC are critical to their successful application in future extreme environment applications. Affordability permeates throughout the development from the development of the basic raw material stock, the development of various forming processes for the fabrication of complex shapes required in airframe applications, and even modeling of the basic material itself. Modeling includes micromechanical models, interface models between the micro-level models and structural design models, and models of the thermalstructural behavior of these hot structures.

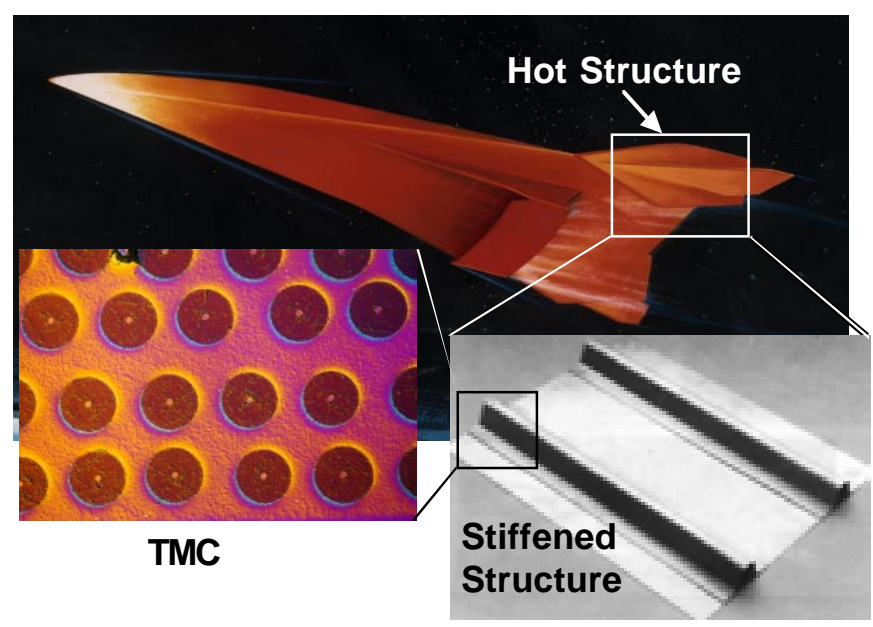

Figure 14. Photograph of a stiffened TMC panel.

\section{Mechanically Attached CMC Structure}

A CMC hot structure joint design methodology for $1200^{\circ} \mathrm{F}$ plus applications is a key need. Under contract to the Air Force, Lockheed Martin employed a design of experiments approach to sort out the key issues needed to design and model these joints. The effort emphasized environmentally stable CMCs along with woven preforms for structural properties. An illustration of the joint concept is shown in figure 15. The joint buildup is analogous to what one might employ for lower temperature polymeric composites. If the joint design development is successful, a subcomponent, such as that illustrated in figure 16, will be fabricated and tested to demonstrate practical application of the concept.

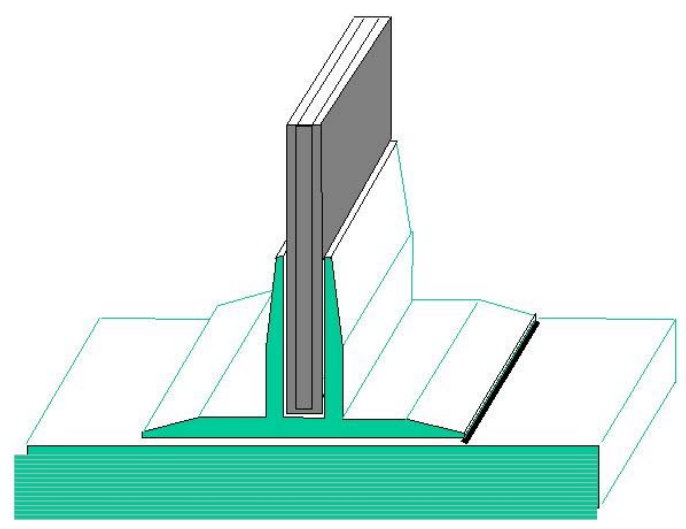

Figure 15. Integrated Hot Structure Joint 


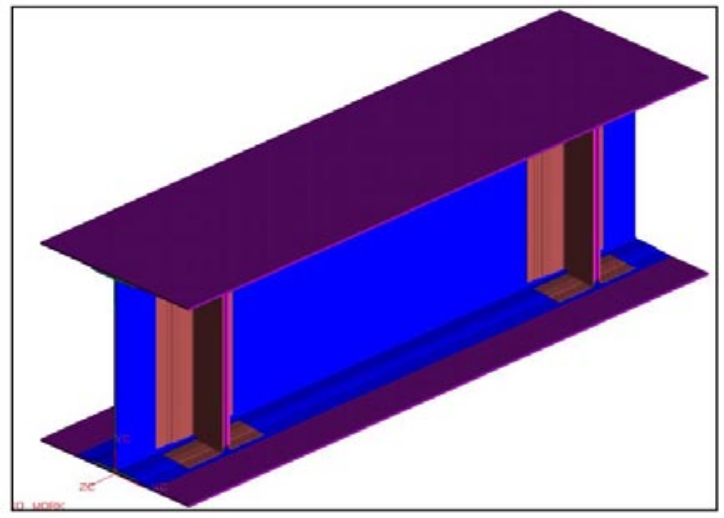

Figure 16. Subcomponent Test of Integrated Hot Structure Joints

\section{Hot Aeroshell Fuselage Fairing}

An "integral" hot structure fuselage, which carries primary loads while using no TPS other than localized insulations to protect non-structural systems, is a farterm concept that will take significant time and effort to develop. Complicating the situation is the requirement to condition a large volume of cryogenic propellant during the ascent mission phases to maintain low propellant losses, and avoid operational issues related to water and air condensation, frosting and cryopumping. A more near-term approach named the METAShield ${ }^{\mathbf{1 3}}$ is being developed which is intermediate between the integral hot structure and a conventional cold primary structure with external acreage TPS. The METAShield concept utilizes several large "aeroshell" structural shells suspended over an integral tank primary fuselage structure. Each shell is lightly loaded by local aerodynamic pressures and its own inertial loads and it transmits these loads to the tank structures through thermally accommodating connections at the two ends and other discrete locations as shown in figure 17.

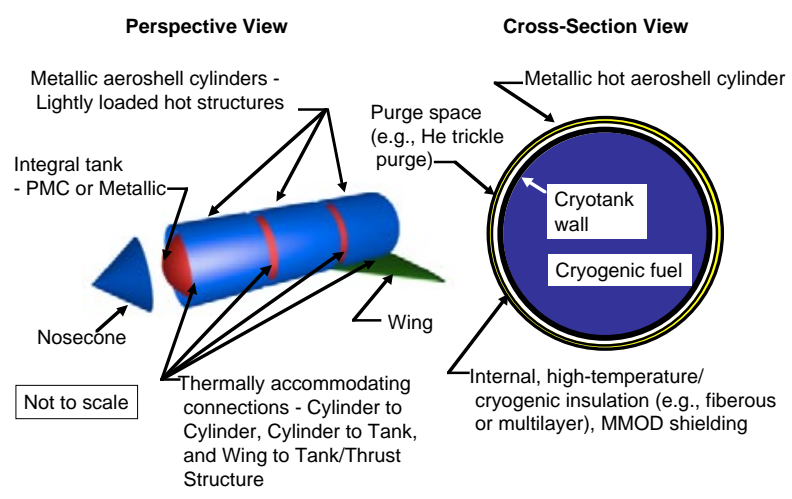

Figure 17. METAshield Metallic Aeroshell Concept (From Reference 13)
Because of the low structural loads, the aeroshells are essentially sized at the minimum gauges normally accepted for aircraft structures (depending on wall construction), and thus can be designed as very durable and structurally efficient hot structures. Nominal aerothermal loads for recent two-stage-to-orbit configurations indicate that peak fuselage OML temperatures aft of the nosecone area will be less than $2000^{\circ} \mathrm{F}$. Thus, state-of-the-art metallic materials are viable options, and their replacement by more advanced, lower weight materials as they mature is relatively straightforward. The primary structures interior to the aeroshells are thermally protected using efficient, low-density fibrous insulation blankets. This insulation performs several functions, it protects against high temperature reentry aerothermal loads, it maintains propellant conditioning during ground hold using a low-flow-rate helium purge, and it - along with the aeroshells - serve to protect the primary structure from orbital debris. This insulation can also be replaced relatively simply as more advanced insulations, such as Multi-Layer or aerogel-based insulations, are developed. The major design challenges for this concept are the thermally accommodating connections and the aerothermal seals between the aeroshells and their penetrations. Thermal-stress analysis results for a shear bellows for connection between an aeroshell and a primary structure (not shown) are shown in figure 18 . Though the stresses in the aeroshell are small, the shear bellows support system has unacceptably large stresses due to its inability to adequately accommodate the thermal growth of the aeroshell. Alternate design approaches are being evaluated to alleviate these thermal stresses.

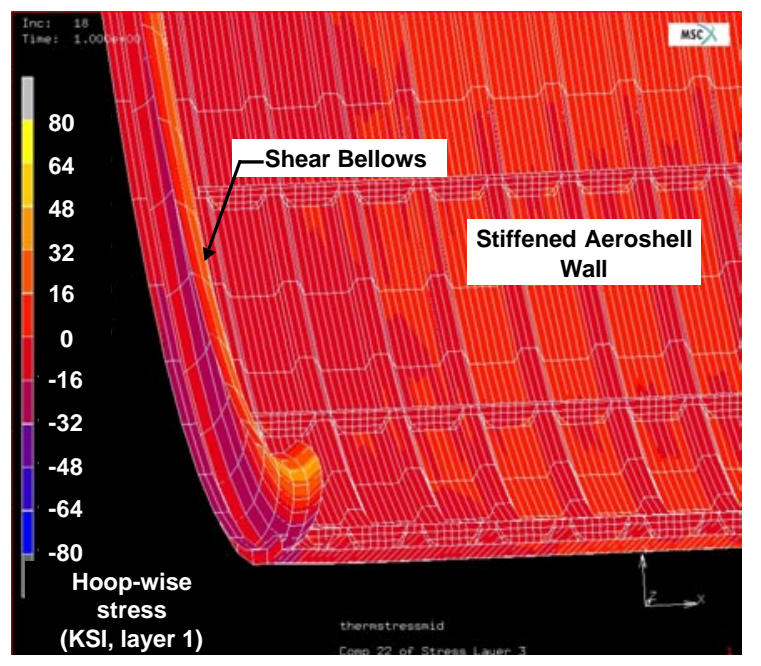

Figure 18. Hoopwise thermal stresses for METAShield shell and shear bellows support system (From Reference 13) 


\section{Observations and Conclusions}

This overview of structures and materials technologies suitable for the extreme environments encountered by earth-to-orbit space transportation systems could only summarize a few specific research areas. For example, a significant effort underway to mature control surface structures and leading edges was not covered. In addition, an initial effort to develop a ceramic matrix composite propellant tank was not discussed. Also the advances in processing and manufacturing scaleup, and in oxidation protection, non-catalytic, high emissivity coatings could only be hinted at. The stated objective in developing these technologies is a shifting of goals from maximum performance to dramatic improvements in costs, in operations time, and in safety. However, without adequate operational experience, it is difficult to quantify these improvements. It would not be unexpected that at least initially, these maturing concepts may under perform their more state-of-the-art brethren. However, at least conceptually, the new TPS and hot structure technologies described have qualities that indicate a high potential for safe and cost effective operation, but the objective data is still lacking. So the development plans are to mature these technologies (through several generations if required) to the point where they can be utilized in ground or flight demonstrations, and generate the needed operational data to allow routine, safe reusable launch vehicles.

\section{Acknowledgements}

The authors would like to acknowledge the contributions of the Boeing Company, Lockheed Martin, Goodrich Aerostructures, Oceaneering, Aztex, and COI Ceramics. In addition, the editorial comments of Dr. Max Blosser were greatly appreciated.

\section{$\underline{\text { References }}$}

[] Morris, W. D., White, N. H., and Ebeling, C. E. , "Analysis of Shuttle Orbiter reliability and maintainability data for conceptual studies", AIAA Paper 96-4245, Space Programs and Technologies Conference, Huntsville, AL, Sept. 24-26, 1996

[2] Pate-Cornell, M. Elisabeth, and Fischbeck, Paul S., "Risk Management for the Tiles of the Space Shuttle", Interfaces 24:1 January-February 1994, pp. 64-86.

[3] Blosser, M.L.: "Advanced Metallic Thermal Protection Systems for Reusable Launch Vehicles", Ph.D. Dissertation, UVA, May 2000.
[4] Bohan, H.L., Shideler, J.L., and Rummler, D.R.: "Radiative Metallic Thermal Protection Systems: A Status Report", Journal of Spacecraft and Rockets, Vol. 14, No10, October 1977, pp. 626-631.

[5] Blair, W., Meaney, J.E., and Rosenthal, H.A.:'Fabrication of Prepackaged Superalloy Honeycomb Thermal Protecton System (TPS) Panels", NASA CR3755, October 1985.

[6] Bouslog, S. A.; Moore, B.; Lawson, I.; and Sawyer, J. W.: "X-33 Metallic TPS Tests in NASA-LaRC High Temperature Tunnel", AIAA 99-1045, 37 ${ }^{\text {th }}$ AIAA Aerospace Sciences Meeting and Exhibit, January 1114, 1999, Reno, NV.

[7] Blosser, M., Chen, R.; Schmidt, I.; Dorsey, J.; Poteet, C.; and Bird, K.: "Advanced Metallic Thermal Protection System Development", AIAA-2002-0504, $40^{\text {th }}$ AIAA Aerospace Sciences Meeting and Exhibit, January 14-17, 2002, Reno, NV.

[8] Blosser, M. and Chen, R.:"Metallic Thermal Protection System Panel Flutter Study", AIAA-2002$0501,40^{\text {th }}$ AIAA Aerospace Sciences Meeting and Exhibit, January 14-17, 2002, Reno, NV

[9] Poteet, C.C., and Blosser, M. L.: "Improving Metallic Thermal Protection System Hypervelocity Impact Resistance Through Design of Experiments Approach", AIAA 2002-0912, 40 ${ }^{\text {th }}$ AIAA Aerospace Sciences Meeting and Exhibit, January 14-17, 2002, Reno, NV

[10] U.S. Congress, Office of Technology Assessment: "Round Trip to Orbit: Human Spaceflight Alternatives Special Report”, OTA-ISC-412, Washington, DC: U.S. Government Printing Office, August 1989.

[11] Hales, S.J.; Saqib, M.; and Alexa, J.A.: An innovative method for manufacturing $\mathrm{g}$-TiAl foil. Gamma Titanium Aluminides 2003, edited by Kim, Y.-W., Clemens, H. and Rosenberger, A.H., TMS, Warrendale, PA, 2003, pp.xxx-yyy.

[12] R. LeHolm, H. Clemens and H. Kestler, "Powder metallurgy (PM) gamma-based titanium aluminide structures for use in various high temperature aerospace applications", in Gamma Titanium Aluminides 1999, ed. Y.-W. Kim, D.M. Dimiduk and M.H. Loretto (Warrendale, PA: TMS, 1999), 25-33.

[13] Scotti, S.J.; Poteet, C.C.; Daryabeigi, K.; Nowak, R.J.; Hsu, S.Y.; Schmidt, I.H.; and Ku. S.H.P.:

"METAshield - Hot Metallic Aeroshell Concept for RLV/SOV”, NASA TM-2003-212425, July 2003. 